\title{
Variability of the Northern Annular Mode's signature in winter sea ice concentration
}

\author{
Gerd Krahmann \& Martin Visbeck
}

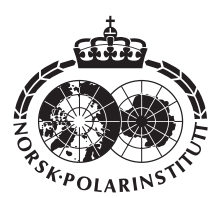

Historical winter sea ice concentration data are used to examine the relation between the Northern Annular Mode (NAM) and the sea ice concentration in the Nordic seas over the past 50 years. The well known basic response pattern of a seesaw between the Labrador Sea and the Greenland, Iceland and Barents seas is being reproduced. However, the response is not robust in the Greenland and Iceland seas. There the observed variability has a more complex relationship with surface temperatures and winds. We divide the sea ice response into three spectral bands: high ( $\mathrm{P}<5$ year), band $(5<\mathrm{P}<15$ year), and low pass ( $\mathrm{P}>15$ year) filtered NAM indices. This division is motivated by the expected slow response of the ocean circulation which might play a significant role in the Greenland and Iceland seas. The response to the NAM is also examined separately for the periods before and after 1976 to identify variations due to the relocation of the northern centre of the North Atlantic Oscillation.

G. Krahmann \& M. Visbeck, Lamont-Doherty Earth Observatory of Columbia University, RT 9W, Palisades, NY10964,USA,krahmann@ldeo.columbia.edu.

The Northern Annular Mode (NAM) is, like the closely related North Atlantic Oscillation (NAO) (Visbeck et al. 2001; Visbeck et al. 2003), a large-scale pattern of atmospheric variability in the northern hemisphere (Thompson \& Wallace 1998). It represents substantial variations of the northern hemisphere mid- and high latitude atmospheric circulation on a broad range of time scales from weeks to multiple decades. As the winds change they exhibit influence on many parts of the climate system such as ocean currents, surface heat fluxes and precipitation. A further component of the system that is strongly influenced by the NAM/NAO is the sea ice in the Arctic. Between high and low states of the NAM/NAO, thickness, concentration, extent and advection of the Arctic sea ice vary substantially (e.g. Deser et al. 2000). Observations revealed that the atmospheric circulation pattern over the Arctic changed substantially over the past decades (Walsh et al. 1996). This change is tight- ly linked to a shift in the preferred state of the NAM/NAO over the same period (Thompson \& Wallace 1998) and has been named as the cause for the observed long term decrease in summer sea ice extent in the Arctic (Chapman \& Walsh 1993; Parkinson et al. 1999; Deser et al. 2000). In contrast to the summer ice extent, the winter sea ice extent has not changed significantly (Deser et al. 2000). It exhibits, however, significant year-to year-variability, which is the subject of our study.

Studies of Arctic sea ice have been able to establish the large-scale pattern of its variations and their evolution over the past decades (e.g. Mysak \& Manak 1989; Deser et al. 2000; Vinje 2001). In particular, the strongest signal in winter sea ice extent (identified as its first empirical orthogonal function) has been found to be highly correlated with the NAM/NAO (Deser et al. 2000; Vinje 2001). It is characterized by a seesaw of concentration anomalies between the Labrador Sea and the Greenland, Iceland and Barents seas. 
When compared to the wind anomalies associated with the NAM/NAO, it appears that most of the sea ice concentration anomalies can be explained by simple wind forced movement. This agreement holds particularly well in the Labrador and Barents seas.

Vinje noted in his study (2001) that while the correlation between the NAO and the April sea ice area in the Barents Sea (his eastern part of the Nordic seas) and the Labrador Sea is very high with -0.97 and 0.81 , respectively, it is weaker in the Greenland/Iceland Sea (his western part of the Nordic seas) with only -0.60 . Although the correlation between the sea ice concentration and the NAM/NAO for the Greenland/Iceland Sea area is negative, observations of the sea ice transport through Fram Strait during high NAM/ NAO index years show increased ice export from the Arctic into the Greenland Sea at least for the period after 1977 (Vinje et al. 1998; Kwok \& Rothrock 1999; Dickson et al. 2000; Hilmer \& Jung 2000). Hilmer \& Jung (2000) noted that the location of the northern centre of the NAM/NAO shifted eastward after 1977. This shift resulted in a high correlation coefficient between Arctic sea ice export and the NAM/NAO of 0.7 whereas before it was only 0.1 . If no process other than a wind anomaly-driven change in sea ice export from the Arctic was involved, one would expect higher sea ice concentrations in the Greenland/ Iceland Sea during a positive NAM/NAO since more ice is advected into the region. Observational data oppose this simplistic idea. Possible processes which could lead to the observed negative correlation between sea ice concentration and $\mathrm{NAM} / \mathrm{NAO}$ in the Greenland and Iceland seas are changes in advection of heat either by the atmosphere or the ocean which then lead to a change in the freezing and melting of sea ice.

In this study we revisit the covariance between the Arctic winter sea ice concentration and the NAM/NAO (Mysak \& Manak 1989; Chapman \& Walsh 1993; Parkinson et al. 1999; Deser et al. 2000). Here we are especially interested in the variability of the response to the NAM/NAO. We examine the questions whether the response of the sea ice depends on the time scale of the NAM/NAO variations and whether the response changed together with the changes of the NAM/ NAO in the 1970s.

\section{Data and methods}

We use the updated version of the sea ice concentration data set of Chapman \& Walsh (1993) as well as sea surface temperatures (SST) and $10 \mathrm{~m}$ wind vectors from the NCEP-NCAR reanalysis (Kalnay et al. 1996) to investigate the relation between the sea ice concentration, SSTs, wind vectors and the NAM index of Thompson \& Wallace (1998). We have calculated the response of winter (January-March) averages of sea ice concentration, SST and wind vectors at each grid point of the the data sets to a typical positive NAM (defined as one standard deviation of its index). The response to a typical negative NAM can be obtained by changing the sign of the results shown in the figures displaying the response to a positive NAM. Note that the response to a strongly positive NAM would typically be twice the shown response and that the difference between strongly positive and negative NAMs can thus amount to four times the shown response. For the calculation we regressed both unfiltered and filtered NAM indices onto the three data sets (sea ice concentration, wind vectors, SST) and multiplied the regression coefficients by one standard deviation of the index. The bands we have used to filter the data are: periods shorter than 5 years (which we denote as high-pass); 5 to 15 years (band-pass); and longer than 15 years (low-pass). We have also separated the time series in two halves to test whether the changes in the location of the NAM/NAO's northern centre of action in the 1970s had any influence on the sea ice response or its variations. The same calculations have been performed with the NAO index but we found no significant difference in the sea ice response. We therefore present only the results from the calculations in which the NAM index was used. The analysis has been restricted to the period after 1950 since sea ice concentration data are more reliable for this time interval.

\section{Analysis}

The wintertime response of the sea ice concentration to the NAM is shown in Fig. 1. The respective index time series are shown in Fig. 2. The basic signature of the sea ice response to the NAM is a seesaw between the concentration anomalies in the Labrador and the Barents/GIN

Variability of the Northern Annular Mode's signature 

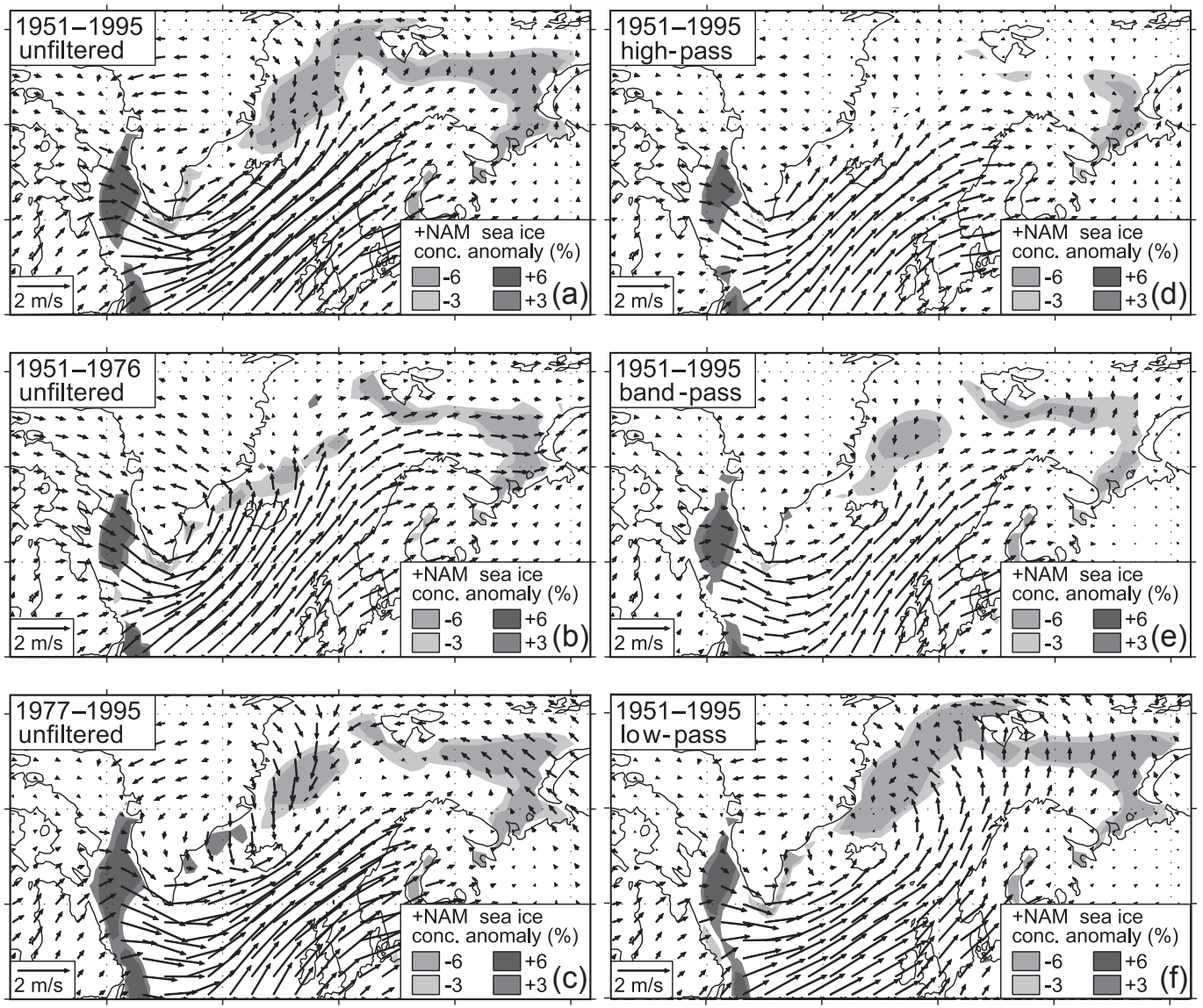

Fig. 1. Winter (January to March) response of the sea ice concentrations from the Chapman \& Walsh (1993) data set to a positive one standard deviation Northern Annular Mode index (Thompson \& Wallace 1998). The six panels show the response for the full time series (1950 to 1998) and the two halves of it as well as the response obtained with high-, band- and low-pass filtered NAM time series. Shaded are levels of $\pm 3 \%$ and $\pm 6 \%$ concentration change. Local response values reach up to $\pm 20 \%$. Overlaid is the response of the $10 \mathrm{~m}$ winds of the NCEP/NCAR reanalysis (Kalnay et al. 1996).

seas regions. This very robust, basic response to a positive NAM is visible in all six graphs in Fig. 1. Virtually no response is found in the Arctic Ocean itself (not shown in the graphs) since the winter sea ice concentration is near $100 \%$ both during high and low phases of the NAM.

When we look at Fig. 1a we can relate the sea ice concentration anomalies during a high NAM/ NAO state to the anomalies of the winds. We find that, while in the Labrador and Barents seas the sea ice concentration response supports the idea of NAM/NAO-related wind anomalies causing changes in the sea ice concentration, this does not hold in the Greenland and Iceland seas region. There we find instead a reduced sea ice con- centration during high NAM index years coinciding with a northerly wind anomaly which causes enhanced southward sea ice transport in Fram Strait and therefore should have resulted in higher sea ice concentrations. The northerly wind anomaly is stronger in the response to the NAO (not shown) than to the NAM, as shown in Figs. 1 and 3 . To better understand the apparent contradiction between expected and observed response we filtered the NAM index and are thereby able to distinguish between response components which act on short time scales and other components which influence the sea ice only on longer time scales. The idea behind this approach is that the wind-driven response acts nearly instantane- 

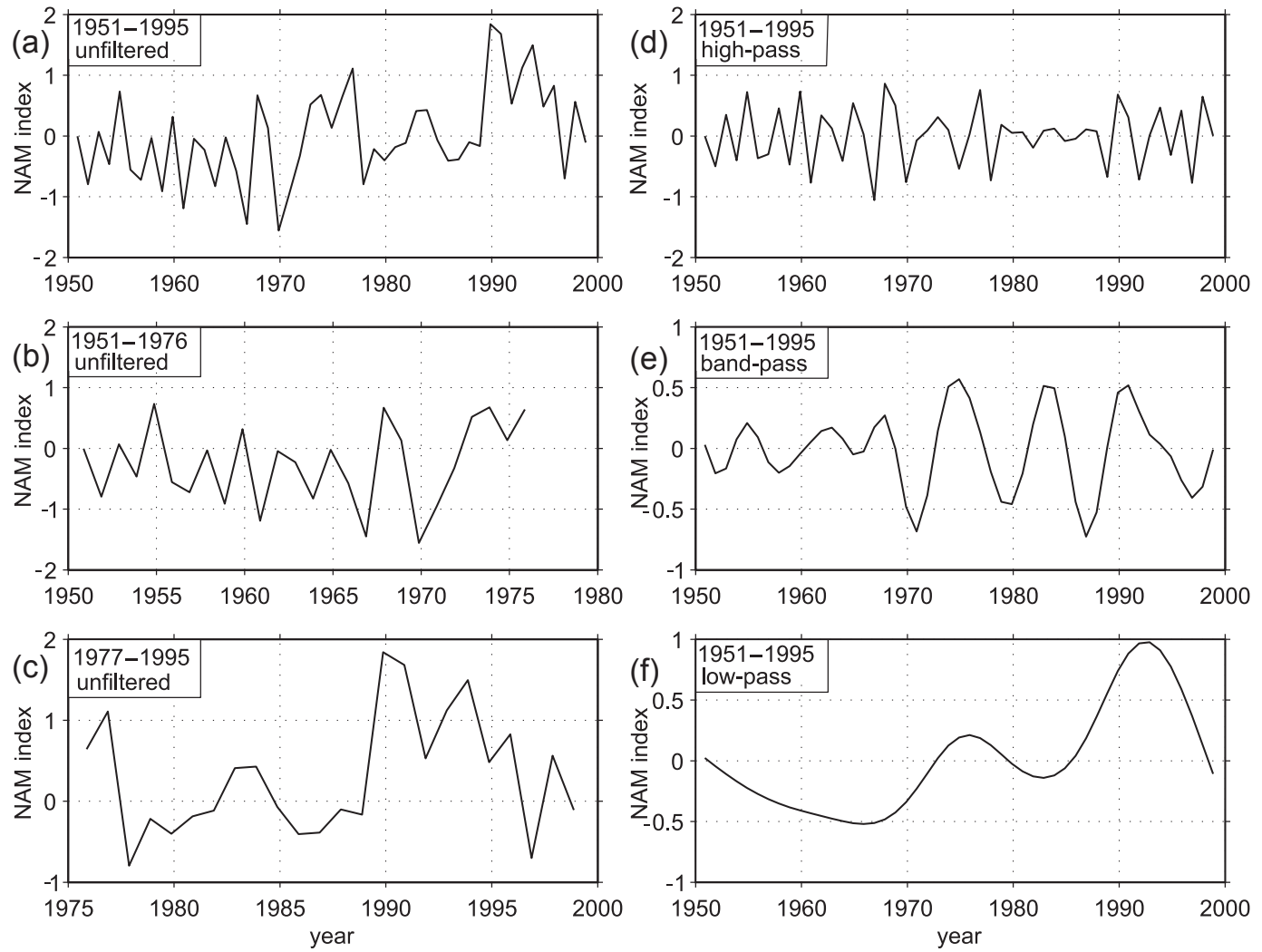

Fig. 2. NAM index time series used to obtain the response values shown in Figs. 1 and 3.

ously whereas the advection of heat by the ocean would take place effectively only on a longer time scale.

The results of the filtered NAM index response are shown in Fig. 1d-f. The sea ice concentration response to the NAM indeed shows a distinct variation with the periodicity of the NAM forcing. The differences are most pronounced in the Greenland and Iceland seas. There we find increasingly negative response with the length of the NAM periodicity. Short periods lead to a negligible response while long periods cause a widespread reduction in sea ice concentration. Only small variations can be seen in the Barents and the Labrador seas. So why does the sea ice concentration in the Greenland and Iceland seas respond differently to different NAM periodicities? As has been shown by Hilmer \& Jung (2000), the sea ice export from the Arctic through Fram Strait increases during a high NAM/NAO. This should cause an increase in sea ice concentration downstream of Fram Strait. Instead we find a decrease. It appears that another process than anomalous advection of sea ice by the wind anomalies is responsible for the negative response to the NAM/NAO. Two processes are likely candidates for this: anomalous atmospheric or anomalous oceanic advection of heat. In Fig. 3 we show the sea surface temperature response and again the wind vector response to the NAM calculated similar to the sea ice concentration response in Fig. 1.

Indeed we find that the SST response in the Nordic seas to the NAM/NAO varies with the periodicity of the NAM/NAO. Short period forcing leads to a relatively weak response in SST, while decadal and longer periods result in a stronger response of which the warm part appears to extend further north-westward with longer forcing periods. This north-westward relocation of the positive SST anomalies from the Norwegian Sea towards the Greenland Sea could be responsible for additional melting of sea ice and thus the negative sea ice concentration response to the

Variability of the Northern Annular Mode's signature 

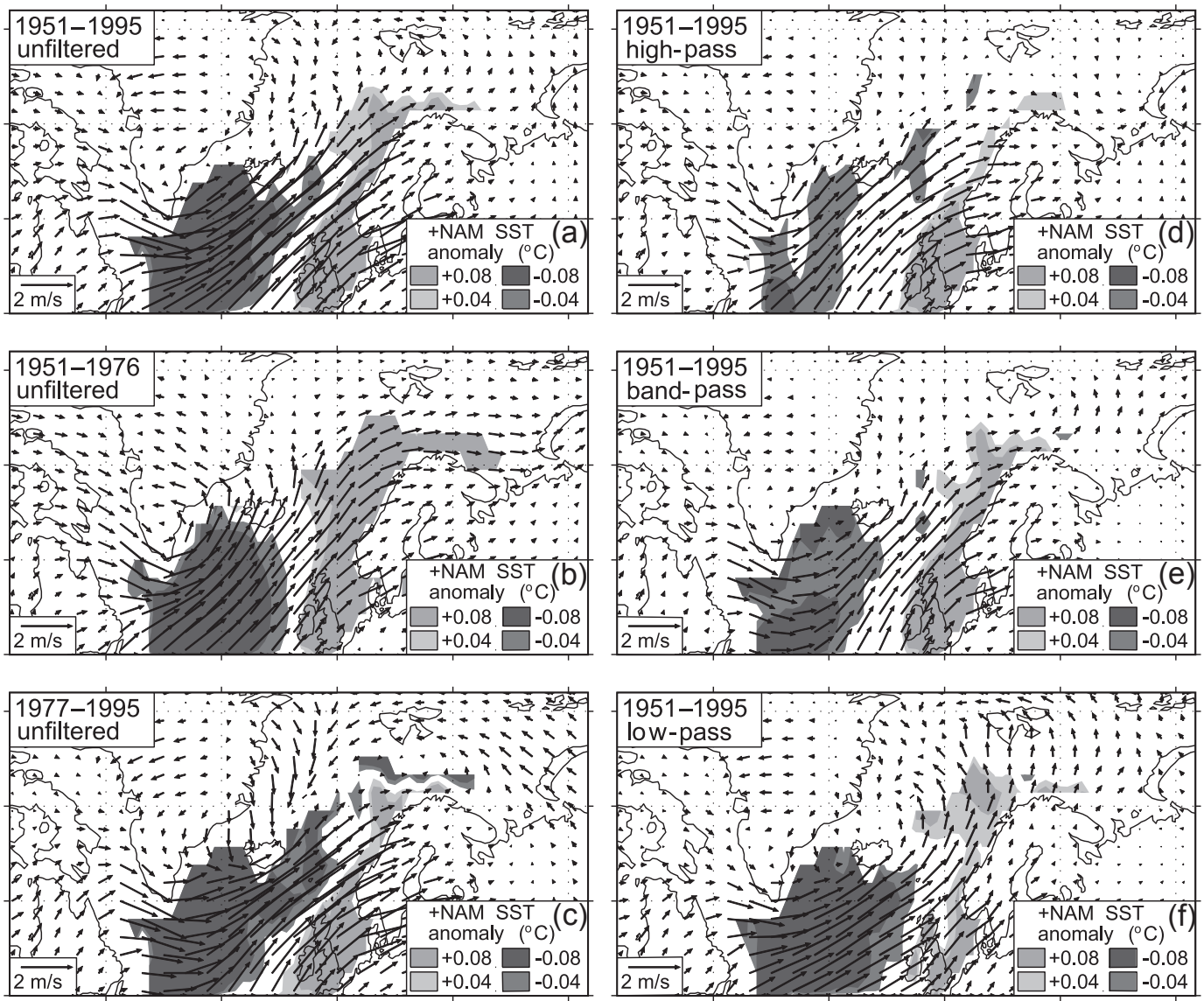

Fig. 3. Winter (January to March) response of the sea surface temperatures from the NCEP/NCAR reanalysis data set (Kalnay et al. 1996) to a positive one standard deviation Northern Annular Mode index (Thompson \& Wallace 1998). The six panels show the response for the full time series (1950 to 1998) and the two halves of it as well as the response obtained with high-, band- and low-pass filtered NAM time series. Shaded are the $\pm 0.04^{\circ} \mathrm{C}$ and $\pm 0.08^{\circ} \mathrm{C}$ temperature changes. Local response values reach up to $\pm 1{ }^{\circ} \mathrm{C}$. Overlaid is the response of the $10 \mathrm{~m}$ winds of the reanalysis data set.

NAM/NAO. What about the anomalous atmospheric advection of heat during a high NAM/ NAO? Could this also cause the melting of the sea ice in Greenland and Iceland seas? Looking at the wind vector anomalies it does appear that enhanced northward transport of heat into the Greenland and Iceland seas region occurs at longer NAM/NAO periodicities. It is thus possible that the atmospheric transport of heat contributes to the variation in sea ice concentration response.

Is the observed SST change sufficient to cause a significant melting of sea ice in the Greenland Sea? Assuming a volume transport of 5 Sv entering the Nordic seas and a temperature change of $0.1^{\circ} \mathrm{C}$, this leads (integrated over one year) to additional heat imported into the Nordic seas, which is sufficient to melt $200 \mathrm{~km}^{3}$ of sea ice. When compared to the average annual Arctic sea ice export through Fram Strait of about $3000 \mathrm{~km}^{3}$ this is a substantial amount of additional heat and could thus cause an earlier, i.e. more northern, melting than normal. Higher upper ocean temperatures during high NAM/NAO phases are corroborated by Dickson et al. (2000) who showed the temperatures of the waters entering the Barents Sea from the Norwegian Sea to be about $0.23^{\circ} \mathrm{C}$ warmer for a 1-sigma higher NAO index.

We have found that the response of the sea ice concentration in the Greenland and Iceland seas to the NAM/NAO depends on the period with which the forcing varies. Hilmer \& Jung (2000) showed that after 1977 the correlation between the NAM/NAO and the sea ice transport through 
Fram Strait changed significantly from 0.1 to 0.7 . Did this change in the sea ice export from the Arctic have any influence on the forcing frequency dependence that we just described? Unfortunately, the time series before and after that change are too short to meaningfully separate the 3 frequency bands. We therefore examine here only the response to the unfiltered NAM index. The resulting response patterns and NAM indices are shown in Figs. $1 \mathrm{~b}$ and c, $2 \mathrm{~b}$ and $\mathrm{c}$ and $3 \mathrm{~b}$ and $\mathrm{c}$.

Variations in the response between the two halves of the time series are again found predominantly along the eastern Greenland coastline. When we compare the later period with the earlier, a change from a negative sea ice concentration response to a positive one is found only in the Irminger Sea, at the downstream end of the East Greenland Current. This is likely caused by the enhanced sea ice export from the Arctic. The response in the Greenland Sea in the middle part of the East Greenland Current in contrast keeps its negative correlation with the NAM/ NAO. The spatial extent of the negative correlation area is, however, smaller than in the response for the whole time series. When we try to relate these changes in sea ice concentration response to the changes in wind anomalies, it appears that some of this is caused by the winds. In the earlier period basically no northerly wind anomalies occurred during a positive NAM/NAO. Instead the enhanced southerly winds over much of the Norwegian Sea resulted in warmer SSTs in the region, possibly both through atmospheric and oceanic advection, though we are not able to distinguish these here. In the later period this wind flow has a more westerly component, resulting in less warming of the Norwegian Sea. The biggest change in the wind response is found along the eastern Greenland coastline. There, enhanced northerly winds occur as NAM/NAO response after the easterward shift of the northern NAM/NAO centre (Hilmer \& Jung 2000). These enhanced northerly winds are responsible for enhanced southward advection of both sea ice and colder air masses. One would therefore expect more sea ice along the eastern Greenland coast and in the adjacent seas. However, according to our analysis this change in the NAM/ NAO was not sufficient to overcome the negative sea ice concentration response in the Greenland and Iceland seas caused by the warmer surface waters.

\section{Summary}

We have analysed a compilation of historical sea ice concentration data (Chapman \& Walsh 1993) for its response to the NAM/NAO. As has been shown by previous studies (e.g. Deser et al. 2000), the dominant signal in the response of the winter sea ice concentration to the NAM is a seesaw in the sea ice extent between the Labrador Sea and the Greenland and Barents seas.

When the sea ice concentration response is put into context with the wind anomalies associated with the NAM/NAO it appears that the Greenland and Iceland seas differ from the Labrador and Barents seas. In the latter two regions the sea ice anomalies are consistent with the variations of wind or atmospheric and oceanic thermal forcing. In contrast, the response in the Greenland Sea south of Fram Strait refutes this idea. Here we find reduced sea ice concentrations as a response to a high NAM/NAO index even though the cold northerly winds and, at least after 1977, the sea ice transport into region are stronger during a high NAM/NAO.

To examine this disagreement we extended the work of the previous studies by separating from the NAM index the periodicities shorter than 5 years, between 5 and 15 years, and longer than 15 years. We then regressed the sea ice concentration data onto the filtered NAM time series. We found one area in which in wintertime a significant dependence of the sea ice response on the frequency of the NAM forcing could be seen: the Greenland and Iceland seas. For NAM periodicities longer than 15 years the reponse was consistent with that of previous studies, i.e. decreased sea ice concentration during high NAM index years. For periodicities shorter than 5 years, however, we found basically no response of the sea ice concentration. When compared to the response to the NAM/NAO in winds and SSTs we see that on the short time scales the enhanced southward advection of sea ice through Fram Strait is balanced by the advection of heat in the atmosphere or the ocean and thus results in a negligible response. When we look at longer time scales a negative response occurs. This suggests that a slow oceanic response is the cause for the enhanced melting and thus the negative response.

We also analysed the periods before and after 1976 separately in order to examine the influence of the observed eastward shift of the northern centre of the NAM/NAO on the sea ice concen-

Variability of the Northern Annular Mode's signature 
trations in the Greenland and Iceland seas. We found that though the response was less negative in the Greenland Sea area in the second part of the time series this variation in response was smaller than those we found in the frequency dependent analysis.

To further study the findings presented here we are currently conducting numerical model experiments in which we apply idealized NAMlike forcing anomalies. The basic experiment idea is similar to that of Visbeck et al. (1998) but applied to an Atlantic plus Arctic model domain. We hope to be able to reproduce the variations in response to the NAM and will present the results in the near future.

Acknowledgements.-We thank two anonymous reviewers for their helpful comments. This study has been supported by the National Aeronautics and Space Administration grant JPLCIT 1217507. This is Lamont contribution no. 6428.

\section{References}

Chapman, W. L. \& Walsh, J. E. 1993: Recent variations of sea ice and air temperature in high latitudes. Bull. Am. Meteorol. Soc. 74, 33-47.

Deser, C., Walsh, J. E. \& Timlin, M. S. 2000: Arctic sea ice variability in the context of recent wintertime atmospheric circulation trends. J. Clim. 13, 617-633.

Dickson, R. R., Osborn, T. J., Hurrell, J. W., Meincke, J., Blindheim, J., Adlandsvik, B., Vinje, T., Alekseev, G. \& Maslowski, W. 2000: The Arctic Ocean response to the
North Atlantic Oscillation. J. Clim. 13, 2671-2696.

Hilmer, M. \& Jung, T. 2000: Evidence for a recent change in the link between the North Atlantic Oscillation and Arctic sea ice export. Geophys. Res. Lett. 27, 989-992.

Kalnay, E., Kanamitsu, M., Kistler, R., Collins, W., Deaven, D., Gandin, L., Iredell, M., Saha, S., White, G., Woollen, J., Zhu, Y., Chelliah, M., Ebisuzaki, W., Higgins, W., Janowiak, J., Mo, K. C., Ropelewski, C., Wang, J., Leetmaa, A., Reynolds, R., Jenne, R. \& Joseph, D. 1996: The NCEP/ NCAR 40-year reanalysis project. Bull. Am. Meteorol. Soc. 76, 437-471.

Kwok, R. \& Rothrock, D. A. 1999: Variability of Fram Strait ice flux and North Atlantic Oscillation. J. Geophys. Res. 104(C3), 5177-5189.

Mysak, L. A. \& Manak, D. K. 1989: Arctic sea-ice extent and anomalies 1953-1984. Atmosphere-Ocean 27,376-405.

Parkinson, C. L., Cavalieri, D. J., Gloersen, P., Zwally, H. J., \& Comiso, J. 1999: Arctic sea ice extents, areas, and trends, 1978-1996. J. Geophys. Res. 104(C9), 20837-20856.

Thompson, D. W. J. \& Wallace, J. M. 1998: Observed linkages between Eurasian surface air temperature, the North Atlantic Oscillation, Arctic sea level pressure and the stratospheric polar vortex. Geophys. Res. Lett. 25, 1297-1300.

Vinje, T. 2001: Anomalies and trends of sea-ice extent and atmospheric circulation in the Nordic seas during the period 1864-1998. J. Clim. 14, 255-266.

Vinje, T., Nordlund, N. \& Kvambekk, Å. 1998: Monitoring ice thickness in Fram Strait. J. Geophys. Res. 103(C5), 10437-10449.

Visbeck, M., Chassignet, E. P., Curry, R. G., Delworth, T. L., Dickson, R. R. \& Krahmann, G. 2003: The ocean's response to North Atlantic Oscillation variability. In J. W. Hurrell et al. (eds.): The North Atlantic Oscillation: climatic significance and environmental impact. Pp. 113-145. Washington: American Geophysical Union.

Visbeck, M., Cullen, H., Krahmann, G. \& Naik, N. 1998: An ocean model's response to North Atlantic Oscillation-like wind forcing. Geophys. Res. Lett. 25, 4521-4525.

Visbeck, M., Hurrell, J. W., Polvani, L. \& Cullen, H. 2001: The North Atlantic Oscillation, present, past and future. Proceedings of the National Academy of Sciences 98, $12876-12877$.

Walsh, J. E., Chapman, W. L. \& Shy, T. L. 1996: Recent decrease of sea level pressure in the central Arctic. J. Clim. 9, 480-486. 